\title{
The Innate Immune System in Acute and Chronic Wounds
}

\author{
Amanda S. MacLeod ${ }^{1, *}$ and Jonathan N. Mansbridge ${ }^{2, *}$ \\ ${ }^{1}$ Department of Dermatology, Duke University Medical Center, Durham, North Carolina. \\ ${ }^{2}$ Histogen, Inc., San Diego, California.
}

Significance: This review article provides an overview of the critical roles of the innate immune system to wound healing. It explores aspects of dysregulation of individual innate immune elements known to compromise wound repair and promote nonhealing wounds. Understanding the key mechanisms whereby wound healing fails will provide seed concepts for the development of new therapeutic approaches.

Recent Advances: Our understanding of the complex interactions of the innate immune system in wound healing has significantly improved, particularly in our understanding of the role of antimicrobials and peptides and the nature of the switch from inflammatory to reparative processes. This takes place against an emerging understanding of the relationship between human cells and commensal bacteria in the skin.

Critical Issues: It is well established and accepted that early local inflammatory mediators in the wound bed function as an immunological vehicle to facilitate immune cell infiltration and microbial clearance upon injury to the skin barrier. Both impaired and excessive innate immune responses can promote nonhealing wounds. It appears that the switch from the inflammatory to the proliferative phase is tightly regulated and mediated, at least in part, by a change in macrophages. Defining the factors that initiate the switch in such macrophage phenotypes and functions is the subject of multiple investigations. Future Directions: The review highlights processes that may be useful targets for further investigation, particularly the switch from M1 to M2 macrophages that appears to be critical as dysregulation of this switch occurs during defective wound healing.

\section{SCOPE AND SIGNIFICANCE}

THIS REVIEW DISCUSSES the basis for the development of chronic wounds that fail to complete the initial clearance of microbial contamination by the innate immune system and stall in a late stage of the inflammatory process. The early inflammatory stage of wound healing is the prov- ince of the innate immune system. This article reviews the complex literature on factors of the innate immune system that affect cutaneous wound healing and potential cellular and molecular mechanisms involved and discusses possible reasons that the innate immune system fails to establish conditions for healing. We

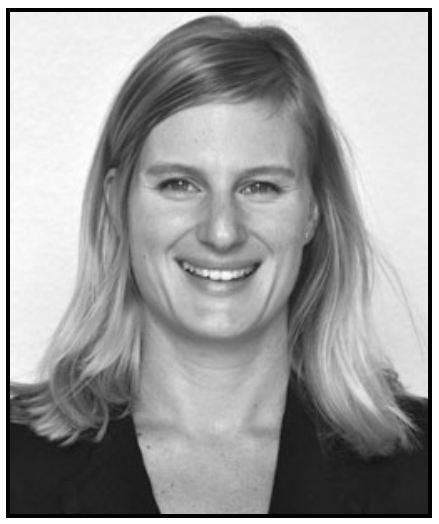

Amanda S. MacLeod, MD

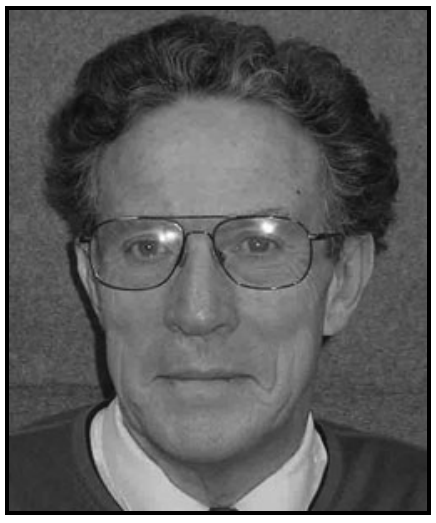

Jonathan N. Mansbridge, PhD

Submitted for publication October 9, 2014 Accepted in revised form December 20, 2014.

*Correspondence: Amanda S. MacLeod, MD, Department of Dermatology, Duke University Medical Center, 40 Duke Medicine Circle, Durham, NC 27710

(e-mail: amanda.macleod@duke.edu);

or Jonathan Noel Mansbridge, PhD, Histogen, Inc., 10655 Sorrento Valley Boulevard, San Diego, CA 92121

(e-mail: jonathanmansbridge@yahoo.com). commercial License (http://creativecommons.org/licenses/by-nc/4.0) which permits any noncommercial use, distribution, and reproduction in any medium, provided the original author(s) and the source are credited. 
will also discuss the switch from inflammation to the reparative phase that ultimately facilitates wound closure. The review will include a discussion of the normal relationship between commensal bacteria that interact with the innate immune system and the cells of the skin. This relationship is extensively modified in chronic wounds.

\section{TRANSLATIONAL RELEVANCE}

Understanding the cellular and molecular mechanisms that lead to impaired wound healing may provide insight into novel aspects to the research on the nature of chronic wounds. Identification of cellular and molecular factors that impair wound healing, such as overt proinflammatory cytokines, dysregulation of macrophages, and imbalance of immunoregulatory molecules such as adenosine and nitric oxide (NO), may provide novel therapeutic targets to aid to the wound healing response.

\section{CLINICAL RELEVANCE}

Understanding innate immunity components that are critical in the early phases of wound healing will inform the design of wound repair therapies and the selection of new targets with the goal of improving wound healing and resolving impaired wounds.

\section{DISCUSSION}

\section{Background}

In normal skin, stable homeostasis and barrier function are established by interaction of resident keratinocytes, dendritic cells (DCs), T cells, mast cells, fibroblasts, and macrophages with each other

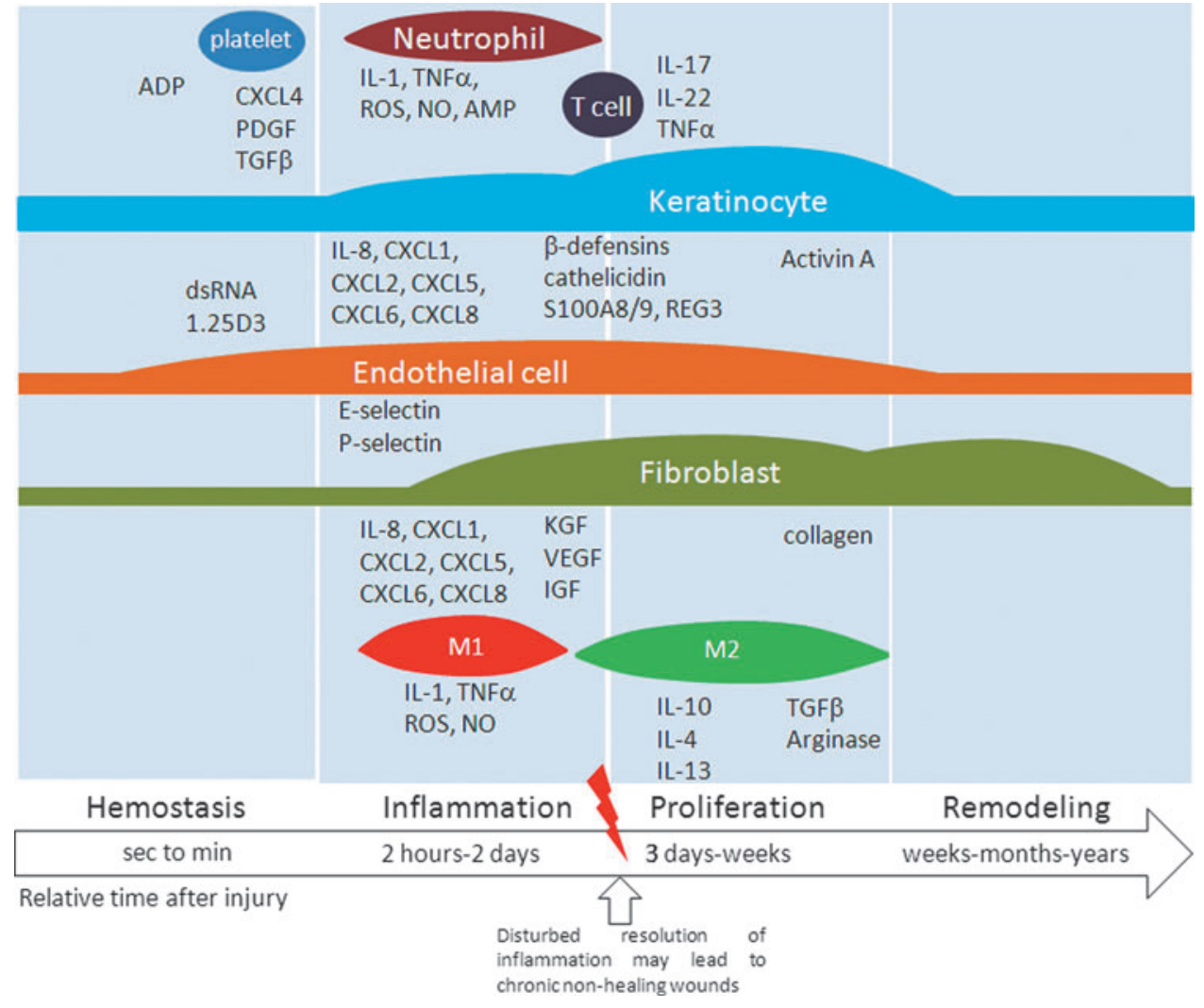

Figure 1. The successive processes of wound healing. Platelet aggregation and release of ADP, PDFG, tumor growth factor $\beta$ (TGF $\beta$ ), and CXCL4 activate the local cells (fibroblasts and keratinocytes) and the immune cascade to initiate inflammation. Keratinocytes, as the major cell type of the epidermis, release proinflammatory cytokines and antimicrobial peptides and proteins (AMPs). Together, this immune response is aimed at decontaminating the wound bed by recruiting neutrophils and macrophages into the wound bed. Neutrophils as well as macrophages are professional microbe-killing cells eliciting reactive oxygen species (ROS), nitric oxide (NO), and AMPs. Meanwhile, endothelial cells in dermal venules express E and P-selectins, which guide the rolling and tethering of extravasating leukocytes to the wound bed. Skin-resident $T$ cell on the one hand and infiltrating $T$ cells on the other hand participate in the inflammatory stage through production of interleukin (IL)-17, IL-22, and tumor necrosis factor $\alpha$ (TNF $\alpha$ ) further amplifying the host defense response. In addition, skin-resident T cells can also produce growth factors, which stimulate keratinocyte proliferation. Activation of macrophages, neutrophils, and keratinocytes leads to sterilization of the wound and subsequently to resolution of inflammation. At this time, proliferation of keratinocytes and fibroblasts stimulates wound closure. This step is directed through the fine regulation of inflammatory to reparative processes and a switch in the cytokine micromilieu of the wound. Macrophages, which are active in the inflammatory phase, termed M1 macrophages, undergo a phenotypic switch to an anti-inflammatory and reparative M2 phenotype. This switch is tightly regulated by cytokines and other molecules further depicted in Fig. 4. M2-like macrophages activate fibroblasts to produce growth factors that stimulate keratinocyte proliferation and migration. 
and with the resident microbiome. When the skin barrier is breached, acute wound healing follows a well-coordinated series of processes, ${ }^{1}$ illustrated in Fig. 1, comprising inflammation, proliferation, and remodeling phases. Each stage is activated by a series of cytokines and other mediators, which are, in part, released as the stage before approaches completion. In chronic wounds, this orderly progression appears to be halted somewhere in the late inflammatory stage before the initiation of wound closure. The arrested stage does not adequately pass on the signals for wound closure, but instead sets up a quasistable equilibrium with resident bacteria. Consequently, the wound does not heal, but forms an ulcer that can last for years. This inflammatory stage of wound healing is the province of the innate immune system. In the development of chronic wounds, at least two mechanisms of arrest may be considered. In the first, a process never reaches the level of completion at which signals, for example, growth factor production, initiating the next stage, for example, keratinocyte proliferation, are generated. In the second, a process, such as inflammation, follows a defined trajectory to completion and moves on to the next stage. If that first step does not complete its function (e.g., clearance of contamination) and the next step is inappropriate (e.g., wound closure), the wound healing response may stall. Examples of both these mechanisms may be found in the development of chronic wounds as discussed below.

The innate immune system comprises a diverse range of defense systems that act to provide primary protection against the harmful agents. The innate immune system includes macrophages, neutrophils, interferons (IFNs), interleukins (ILs), antimicrobial peptides and proteins (AMPs), mast cells, eosinophils, and acute-phase proteins, as well as the physical barrier established by the stratum corneum. The innate immune system is capable of very rapid activation and deployment in response to pathogen-associated molecular patterns (PAMPs) or danger-associated molecular patterns (DAMPs) through the Toll-like receptor (TLR) systems and other innate immune receptors to recognize viruses, bacteria, endogenous or exogenous danger signals, or foreign particles. The innate immune system interacts and instructs the adaptive immune system to elicit optimal immune responses, as recently discussed. ${ }^{2}$

\section{Host-microbiome interactions in healthy and wounded skin}

It has recently become evident that barrier function and control of responses to microorgan- isms in normal skin are complex and involve the establishment of a synergistic ecology between the host and colonizing microbiome. ${ }^{3}$ Human skin is colonized by a diverse skin microbiome. Many of these skin microorganisms are harmless. Symbiotic microorganisms occupy a wide range of skin niches and protect against invasion by more pathogenic or harmful organisms. Commensal organisms such as strains of Staphylococcus epidermidis found in the skin secrete compounds that are themselves antibacterial, such as phenol-soluble modulins, ${ }^{4,5}$ and also interact with the host to induce AMP expression ${ }^{6}$ or reduce inflammation. ${ }^{6}$ This interactive host-microbiome system was thought to be restricted to the stratum corneum, but it has become evident that the system extends further into the living layers of the skin as commensal organisms or their products have been detected in the subcutis in healthy skin. ${ }^{7}$ The composition of the skin microflora varies in different regions of the body and, to lesser degrees, in different individuals and from time to time. ${ }^{8}$ Following injury, this stable and mutually beneficial host-microbiome system is disturbed. Bacterial products stimulate the innate immune system and thus play a role in the inception of inflammation, and commensal skin bacteria invade and become pathogenic upon breach of the skin barrier. If the disturbance is minor, inflammation is minimal as in sterile suction blister wounds. ${ }^{9}$ However many bacteria, including both commensal bacteria, such as $S$. epidermidis, and opportunistic microbes are capable of forming biofilms. ${ }^{10}$ If this occurs, these microbes change their metabolism ${ }^{11}$ and a new ecology is set up with a modified microbiome. ${ }^{12,13}$ The species composition of the bacterial communities in chronic wounds may differ from normal skin, but presumably also show species similarities and may persist for many years. However, molecular studies have been unable to identify a unique organism that colonizes wounds of the same general type, for example, in diabetic foot ulcers or venous leg ulcers. ${ }^{14}$ This is in contrast to burn wounds, in which a causative microbiological agent is usually readily identifiable. Burn wounds often become infected with Streptococcus pyogenes, Pseudomonas aeruginosa, or enterococci. ${ }^{15}$ It has been suggested that chronic wounds may benefit if treated by modifying the nonhealing wound microbiome using probiotics. ${ }^{16}$

\section{Inflame or not to inflame: the role of normal and abnormal inflammation}

Following initial hemostasis, inflammation is a critical part of the normal wound healing process. 
The importance of inflammation is believed to lie in the clearance of contaminating microorganisms. Inflammation may involve cells, such as macrophages, neutrophils, proinflammatory cytokines, vasoactive amines, reactive oxygen species (ROS), NO, extracellular adenosine triphosphate (eATP), double-stranded ribonucleic acid (dsRNA), hyaluronic acid, uric acid, eicosanoids, AMPs, and other mediators, which in concert create, trigger, or amplify skin inflammatory responses. Early events in the innate immune response to skin injury include the recruitment of neutrophils and the induction of antimicrobial peptides, particularly, in humans, the cathelicidin LL-37. ${ }^{17}$ Neutrophils are recruited by a series of asparagine-leucinearginine (ELR) motif-containing CXC chemokines that are secreted by keratinocytes and fibroblasts and subsequently by neutrophils and macrophages. Cathelicidins are produced by neutrophils, keratinocytes, and other cells. The rapidity of this response and the resulting microbicidal activity are essential to kill planktonic bacteria and to prevent the establishment of biofilms and other stable microbial communities. ${ }^{18}$ In the absence of effective microbial decontamination, prolonged inflammation may enter a chronic state prone to failure to heal. Bacterial colonization does not necessarily cause inflammation, ${ }^{6,19,20}$ but high endotoxin levels and other microbial products can drive inflammatory responses. Prolonged inflammation leads to increased levels of proteases that degrade extracellular matrix (ECM) and growth factors. ${ }^{21,22}$ This hampers the wound entering the proliferative phase to facilitate wound closure. Interestingly, suction blister wounds, where the blister roof is still intact, do not show substantial inflammation, ${ }^{9}$ whereas excisional wounds, ultraviolet (UV)-induced skin damage, superficial tape stripping or chemical skin irritants, and contact sensitizers cause inflammatory infiltrates, ${ }^{17,23-26}$ suggesting that the route of trauma and the degree and nature of disruption may play an important role.

\section{Antimicrobial host defense proteins in injured skin}

Healthy mammalian skin comprises cells and molecules that are poised to provide a first line of defense against microbial pathogens and to increase immunity in response to tissue injury or microbial threats. AMPs provide a soluble barrier that forms a strong impediment to microbial invasion. AMPs, such as hBD1 and S100A7, S100A8, and S100A9 proteins, are present under homeostatic conditions, whereas other AMPs, such as cathelicidin, hBD2, hBD3, and regenerating islet- derived protein 3A (REG3A), require induction through environmental or endogenous triggers. Previous studies on AMPs revealed several mechanisms of how AMPs protect the host from infections and how they act as multifunctional effector molecules to assist wound healing (Figs. 2 and 3). In addition to their antimicrobial functions, AMPs also regulate keratinocyte growth and differentiation, cytokine production, and influence adaptive immunity. ${ }^{25,27,28}$ Abnormal or dysfunctional AMP production has been associated with susceptibility to microbial infections and several other cutaneous diseases, including nonhealing wounds. ${ }^{29}$ In fact, recent mouse studies further revealed that murine $\beta$-defensin 3 (the ortholog of hBD2) and Reg3 $\gamma$ (ortholog of REG3A), but not S100A8, have wound healing-promoting properties as they could rescue defective wound healing in IL-17 $\mathrm{A}^{-1-}$ mice, which show defective AMP induction. ${ }^{6,30}$

Upon skin injury, the protective skin barrier is breached and the skin becomes more vulnerable to invasion of microbes. Recognition of microbial products and endogenous danger molecules that generate an AMP response are critical components to mount host protection. The innate immune system senses invading microbes, their products, and host-generated danger signals, such as degraded hyaluronic acid and eATP, through classical pathogen recognition receptors (PRRs) or other innate immune receptors. These include TLRs, purinergic receptors, the receptor for advanced glycation endproducts (RAGE), and others. In addition to their well-known role as effectors of innate immunity by killing microbes, AMPs have additional roles as proteinase inhibitors, chemokines, neuropeptides, and in vascularization, which may contribute to their broad function in wound repair. ${ }^{27}$

Many AMPs are small cationic peptides binding to and interacting with the negatively charged membranes of microbes and are thereby able to kill the microbe through membrane disruption, whereas other AMPs inhibit bacterial metabolism or growth. ${ }^{31,32}$ In the case of infection, inflammation, or injury, many AMPs in the skin are increased due to upregulated synthesis by keratinocytes and deposition from degranulation of recruited neutrophils and other immune cells. AMP expression is highly dependent on the cytokine milieu present in the skin and proinflammatory cytokines, such as IL-1, IL-6, IL-8, and tumor necrosis factor $\alpha(\mathrm{TNF} \alpha)$, are typically strong inducers of AMPs, whereas IL-4, IL-13, and IL-10 have been shown to dampen AMP responses. ${ }^{33-35}$ AMPs can amplify the proinflammatory cytokine response and can thus, in some circumstances, assume 
pathogenic roles as in psoriasis, rosacea, and other skin diseases. ${ }^{36-38}$ Human $\beta$-defensins are a wellcharacterized group of AMPs that are abundantly expressed by multiple cell types such as keratinocytes and peripheral blood mononuclear cells (PBMCs). In the skin, hBD1 is constitutively expressed, whereas hBD2 and hBD3 are highly upregulated upon wounding. In inflamed skin, in-
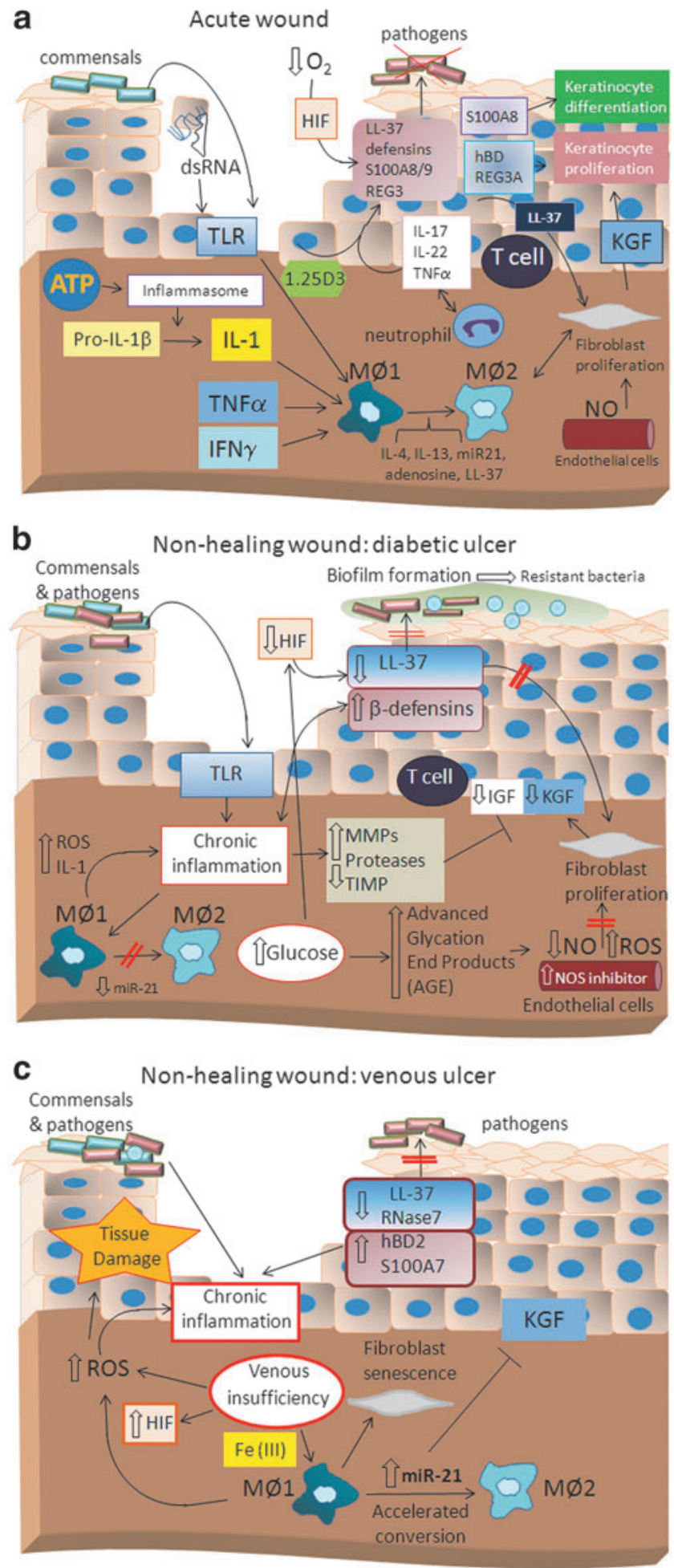

cluding psoriasis and skin injury, hBD3, which like hBD2 was originally purified from psoriatic skin, is inducible by skin injury. ${ }^{38} \mathrm{IL}-1, \mathrm{TNF} \alpha, \mathrm{IFN} \gamma, \mathrm{IL}-17$, and IL-22 are strong inducers of hBD2 and hBD3 expression. ${ }^{25,36,39}$ Furthermore, hBD2 expression is induced by high calcium concentrations and 1,25 vitamin $\mathrm{D}_{3} .{ }^{36}$

Similar to defensins, cathelicidin is derived from a precursor molecule called human cathelicidin antimicrobial protein (hCAP18) that can release an antimicrobial peptide after cleavage. In man, one cathelicidin gene, named human cathelicidin antimicrobial peptide (CAMP), has been identified that encodes the $18 \mathrm{kD}$ pre-pro-protein, hCAP18, which includes the C-terminal human antimicrobial peptide, LL-37. Cathelicidin LL-37 is the best studied cathelicidin peptide in man, whereas in mice, Camp refers to the gene encoding cathelicidin-related antimicrobial peptide (CRAMP). Although expressed in only very low levels in epidermal keratinocytes under resting conditions, it is found in high levels in neutrophils, monocytes, natural killer (NK) cells, and T cells. ${ }^{40,41}$ Wound

Figure 2. Model of (a) normal wound healing in acute wounds and nonhealing (b) diabetic and (c) venous ulcers. Acute wound healing is characterized by activation of the innate immune system aimed at the successful killing of pathogenic microbes through deployment of antimicrobial effector molecules called AMPs, such as cathelicidin LL-37, $\beta$-defensins, and S100 proteins, as well as regenerating islet-derived protein 3 (REG3). Activation of Toll-like receptor (TLR) and other pathogen or danger recognition receptors leads to inflammasome activation and IL-1 production as well as an antimicrobial peptide response. Furthermore, AMP responses are enhanced by low $\mathrm{O}_{2}$ levels in the wound, known to activate HIF1a and through IL-17 and IL-22 produced by resident T cells at the site of injury. IL-1, TLR activation, and interferon (IFN) $\gamma$, as well as TNF $\alpha$ drive M1 macrophage differentiation. Following successful decontamination of the wound, the inflammatory phase resolves and the reparative stage, which is characterized by keratinocyte and fibroblast proliferation, begins. The switch from M1 macrophages to M2-like macrophages as well as distinct AMP function is an important regulator of the reparative phase. Wound reepithelialization requires regulated keratinocyte proliferation, migration, and differentiation, which is guided, at least in part, through growth factor production and AMPs. However, under pathogenic conditions, such as diabetic ulcers (b), the normal wound healing response is disturbed. Diabetes is associated with a chronic inflammatory state, which leads ultimately to an imbalance and dysregulation of skin immune function. Dysfunctional AMP, ROS, and protease production result in overt perpetuation of inflammation, tissue destruction, and ineffective decontamination of pathogenic bacteria. High glucose levels are associated with high levels of AGE products ultimately enhancing vascular NO synthase inhibitor, thereby inhibiting NO production. In contrast, venous insufficiency in venous ulcers (c) leads to iron overloading of macrophages, which engulf extravasated erythrocytes. Iron overloading in macrophages has been shown to give rise to M1 macrophages. However, high abundance of miRNA-21 has been associated with accelerated conversion to M2-like macrophages, leading to the paradox that despite increases in inflammatory M1 macrophages, large numbers of M2-like macrophages are generated prematurely. In addition, miRNA-21 inhibits growth factor signaling by yet undefined mechanisms and delays wound closure. 


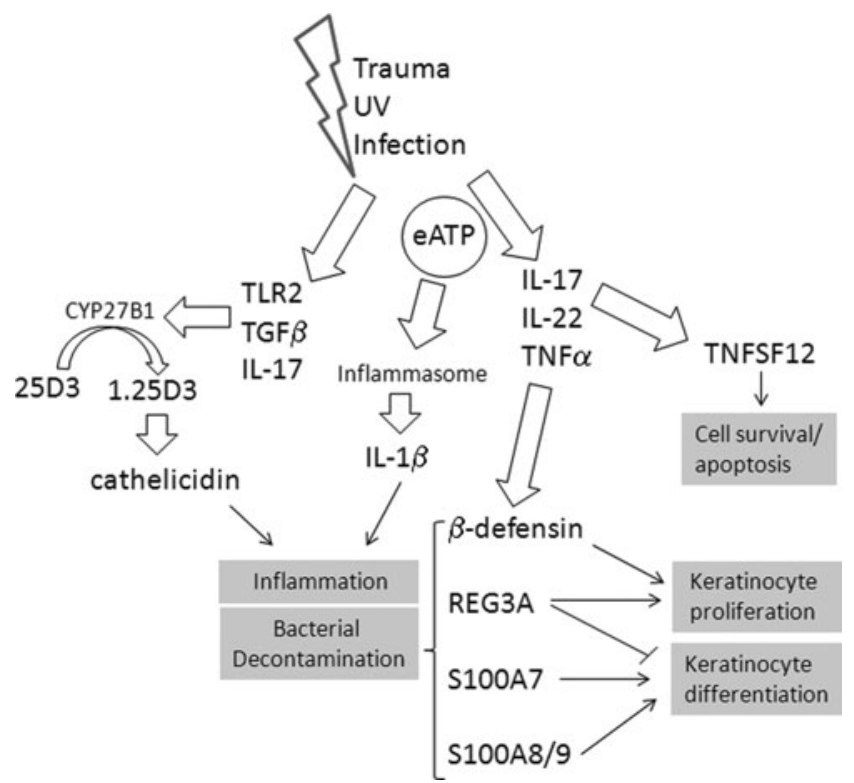

Figure 3. Role of innate immunity in skin wounds. Upon skin injury, the innate immune system becomes rapidly activated. TLR activation-induced CYP27B1 expression converts inactive 24D3 to $1.25 \mathrm{D} 3$, which is a strong inducer of cathelicidin antimicrobial peptide. TLR, IL-1, IL-17, and IL-22 signaling induces multiple antimicrobial molecules, such as $\beta$-defensins, REG3A, S100A7, S100A8, and S100A9. IL-17 and IL-22 are derived from skinresident $T$ cells and their activation is enhanced through purinergic signals, such as through extracellular adenosine triphosphate (eATP). Cathelicidin acts not only as a potent antimicrobial agent to kill gram-positive bacteria but it also serves immunomodulatory functions and can perpetuate inflammation. $\beta$-defensins also have a relatively broad spectrum of antibacterial activity toward gram-positive bacteria and enhance inflammation by recruiting immune cells to the wound site through their chemoattractive properties. S100A7 and S100A8/A9 have antimicrobial activity toward grampositive and gram-negative bacteria. Together, the antimicrobial activity of various host defense peptides and proteins facilitates wound decontamination, a prerequisite for normal wound healing. $\beta$-Defensins and REG3 proteins, but not S100A7 or S100A8/A9, have been shown to stimulate keratinocyte proliferation, which is important for wound reepithelialization and repair. In addition, keratinocyte apoptosis and differentiation are critical to epithelial remodeling and reestablishing the skin barrier. These processes are regulated, at least in part, by S100 proteins and through TNFSF12, recently shown to be induced by IL-17 signaling.

fluids and skin wounds show elevated levels of cathelicidin expression in keratinocytes and other immune cells, reaching a maximum at $48 \mathrm{~h} .^{29}$ hCAP18 is detected in the inflammatory infiltrate and in the epithelium migrating over the wound bed. Using a noninflammatory ex vivo wound healing model comprising organ-cultured human skin, it has been shown that hCAP18 is strongly expressed in healing skin epithelium and that treatment with affinity-purified antibodies raised against LL-37 inhibits reepithelialization in a concentration-dependent manner. ${ }^{29}$

Induction of cathelicidin in human keratinocytes and monocytes in skin wounds or upon infection is enhanced by 1,25 vitamin D3. ${ }^{42,43}$ Interestingly, induction of cathelicidin by 1,25 vitamin $\mathrm{D}_{3}$ in murine cells is absent probably due to the absence of a vitamin D-responsive element in the murine cathelicidin promoter. ${ }^{43}$ In chronic wounds, cathelicidin is one element of host defense molecules that shows marked changes. Cathelicidin is low in venous leg ulcers and absent at the margin of other nonhealing wounds. ${ }^{29}$ In contrast, expression of other AMPs, such as S100A7, ribonuclease 7 (RNase7), hBD2, and hBD3, is not reduced in chronic wounds, but remains unchanged or is upregulated. ${ }^{44}$

S100 proteins comprise a large family of lowmolecular-weight proteins that are characterized by the presence of calcium-binding EF-hands. The majority of S100 genes are located within the epidermal differentiation complex on chromosome 1.q21, and 13 S100 proteins are expressed in normal and/or diseased epidermis. Many S100 proteins are overexpressed in skin cancer, metastasis, psoriasis, arthritis, wound healing, and inflammation. ${ }^{45}$ A relevant role in host defense function has been shown for S100A7, S100A8 (calgranulin A), S100A9 (calgranulin B), S100A12, and S100A15. ${ }^{45}$ S100A7 and S100A8 are strongly regulated by IL-17 and IL-22 in keratinocytes. ${ }^{25,39}$

\section{Inflammatory cytokines and their receptors in the normal and dysfunctional wound healing response}

Keratinocytes, endothelial cells, fibroblasts, DCs, neutrophils, monocytes, macrophages, and innate lymphocytes such as NK cells, $\gamma \delta$ T cells, as well as skin-resident $\mathrm{T}$ cells play major roles in the immune response of wound healing. They produce large amounts of cytokines to initiate and regulate inflammation. In the early stages of normal wound healing, innate immune cells produce proinflammatory cytokines that exacerbate host defense functions by inducing antimicrobial molecules, attracting leukocytes, and creating an environment to protect from microbial infection. In the late stages of the inflammatory phase of wound healing, macrophages are found to switch from a proinflammatory to an alternatively activated phenotype, which has been assumed to be requisite for the switch from the inflammatory to the proliferative stages in wound healing as discussed below in more detail. ${ }^{46}$ Although much work has been done, the defining mechanisms for chronic nonhealing wounds are not exactly known. What we do know is that nonhealing wounds are characterized by a dysregulation of the late inflammatory stage as nonhealing wounds rarely enter the proliferative phase of wound healing. Alterations in macrophage phenotypes and associated cytokine patterns play a critical role in the pathogenesis of nonhealing wounds. 
Interleukin-8. IL-8 (CXCL8), formerly known as neutrophil-activating peptide-1, is one of a group of chemokines, including CXCL1, 2, 3, 5, 6, and 8, that are neutrophil chemokines through a highaffinity receptor, CXCR2, and neutrophil activators through a low-affinity receptor, CXCR1. CXCR2 ${ }^{-1-}$ mice display impaired neutrophil recruitment and delayed wound healing. ${ }^{47,48}$ These chemokines are characterized by the sequence ELR at their $\mathrm{N}$-terminus. Removal of this sequence by matrix metalloproteinase 9 (MMP9) proteolysis causes, in the case of CXCL8, a 10-fold increase in its activity. ${ }^{49}$ This contrasts with the effect of proteolysis on later stages of wound healing, where MMP9 may cause breakdown of protein factors needed to orchestrate wound closure. MMP9 thus represents a double-edged element important in the early stage of wound healing, but destructive if it is not switched off at later stages.

By contrast with the CXCR2 ${ }^{-1-}$ mice, mice depleted of neutrophils using a rabbit antineutrophil serum show faster wound healing than controls. ${ }^{50}$ Likewise, the chemokine receptor, CCR1, which is involved in neutrophil and macrophage recruitment and strongly upregulated after skin injury, is dispensable for wound healing. The CCR1 ${ }^{-1-}$ mouse, in which leukocyte recruitment is impaired, shows no change in wound healing in experimental acute wounds. ${ }^{51}$ The disparity between the expected importance of a major innate immune system component and its dispensability for healing is thought to reflect the differing roles of neutrophils in the noninfected wounds made in the laboratory versus wounds that occur in the natural world that are more likely to be contaminated.

Interleukin-1. Currently, there are 11 members of the IL- 1 family, of which IL- $1 \alpha$ and IL- $1 \beta$ are best characterized. Keratinocytes produce large amounts of IL- $1 \alpha$ and less IL- $1 \beta,{ }^{30,52}$ whereas epidermal DCs, called Langerhans cells, as well as woundinfiltrating macrophages produce mostly IL- $1 \beta$, but not IL- $1 \alpha$. While IL- $1 \alpha$ is translated into a biologically active form, IL- $1 \beta$ is translated as a propeptide that requires processing by caspase- 1 in the inflammasome. However, the secretion pathways and mechanisms of IL- $1 \alpha$ and IL- $1 \beta$ remain a matter of debate. The NACHT, LRR and PYD domains-containing protein 3 (NALP3) inflammasome, comprises a multiprotein complex, which is required for activation of inflammatory caspases such as caspase- 1 . This complex comprises the adaptor protein (ASC) and procaspase-1, both of which are expressed under homeostatic conditions in keratinocytes, and NALP3 whose expression is induced upon wounding. IL- $1 \alpha$ and Il- $1 \beta$ both bind to the IL- 1 type I receptor to elicit an active immune response, whereas binding to IL-1R type II blocks IL-1 activity because it acts as a decoy receptor. IL-1 expression is rapidly induced upon skin injury and is a key player in the wound response by amplifying inflammatory mediators. IL-1 $\beta$ is a key inducer of the antimicrobial response in the skin and is also involved in shaping adaptive $\mathrm{T}$ cell immune responses. IL- $1 \alpha$ levels are low in wound fluids from acute wounds, but are elevated in fluids from chronic wounds. As IL- $1 \alpha$ has been shown to stimulate collagenase production, IL- $1 \alpha$ overproduction may be mechanistically linked to impaired wound healing through cleavage of collagen. ${ }^{53}$ Furthermore, skin injury, induced either by UV radiation, skin irritants, or trauma, has been shown to liberate ATP into the extracellular space, which acts as a trigger for NALP3 inflammasome activation and subsequent IL-1 $\beta$ secretion. ${ }^{30,52,54}$ IL-1 $\beta$ together with IL-23 and IL-6 is important for Th17 differentiation, and IL-17 regulates antimicrobial barrier function as discussed below.

An elegant study by Lee et al. demonstrated that IL- $1 \alpha$ is negatively regulated by caspase- $8 .{ }^{52}$ Caspase- 8 becomes downregulated upon wounding in the granular epidermal layer, and IL- $1 \alpha$ subsequently mediates keratinocyte proliferation in a paracrine manner by first stimulating fibroblasts of the underlying dermis to secrete cytokines, which then induce keratinocyte division. The functional relevance of IL-1 in the wound healing response is somewhat controversial as IL-1R ${ }^{-1-}$ mice do not show differences in the rate of closure of excisional wounds. Skin wounds in IL-1R ${ }^{-/-}$animals have decreased inflammation, decreased collagen levels, and improved restoration of normal skin architecture compared with skin wounds in wild-type mice. ${ }^{55}$ In contrast, mice deficient in the endogenous antagonist of IL-1R (IL-1ra) exhibit impaired wound healing compared with wild-type mice, as evidenced by attenuated collagen deposition and delayed neovascularization. ${ }^{56}$ Conversely, neutrophil recruitment is exaggerated and accompanied by augmented expression of IL-1s, TNF $\alpha$, and CXC chemokines, macrophage inflammatory protein 2-alpha (MIP-2), and $\mathrm{KC}$ together with a failure to induce tumor growth factor $\beta_{1}\left(\mathrm{TGF} \beta_{1}\right)$ and angiogenesis. ${ }^{57}$ This IL-1ra ${ }^{-1-}$ phenotype is strongly reminiscent of an arrest in the transition from proinflammatory to anti-inflammatory macrophage phenotypes seen in chronic wounds.

Tumor necrosis factor $\alpha$. TNF $\alpha$ is a pleiotropic cytokine produced by a variety of cell types, including keratinocytes, macrophages, mast cells, 
and $\mathrm{T}$ cells. There are two types of receptors for TNF $\alpha$ signaling: one TNF receptor with a molecular mass of $55 \mathrm{kDa}$ (TNF-Rp55) and one with a molecular mass of $75 \mathrm{kDa}$ (TNF-Rp75). TNF-Rp55 is expressed ubiquitously in many cell types, whereas TNF-Rp75 expression is predominantly restricted to hematopoietic and endothelial cells. TNF-Rp55 mediates various activities of $\mathrm{TNF} \alpha$, including cytotoxicity, fibroblast proliferation, and induction of superoxide dismutase, whereas TNFRp75 mediates thymocyte and cytotoxic $\mathrm{T}$ cell proliferation. Not surprisingly, $\mathrm{TNF} \alpha$ can act in a beneficial or deleterious mode in the wound healing response in a dose-dependent manner. Elevation of $\mathrm{TNF} \alpha$ leads to decreased production of granulation tissue, whereas low doses of TNF $\alpha$ promote collagen disposition, ${ }^{58-61}$ demonstrating the importance of accurate cytokine regulation during wound healing. $\mathrm{TNF} \alpha$ also suppresses the TGF $\beta$ stimulation of ECM production. ${ }^{62}$ High levels of $\mathrm{TNF} \alpha$ are present in the wound fluid of chronic nonhealing wounds, leading to excessive inflammation ultimately resulting in impaired wound healing and tissue destruction. ${ }^{63}$

Granulation tissue formation is a prerequisite for complete wound closure and healing. There are contradictory reports on the effects of locally applied $\mathrm{TNF} \alpha$ on granulation tissue formation in skin wound healing, ${ }^{59,64,65}$ indicating there is no consensus on the effects of local $\mathrm{TNF} \alpha$ application. Wound healing studies in TNF-Rp55 ${ }^{-/-}$mice showed in enhanced collagen accumulation with reduced leukocyte infiltration at wound sites. ${ }^{66}$

Interleukin-6. Various types of cells, including macrophages, $\mathrm{T}$ cells, fibroblasts, keratinocytes, and endothelial cells, produce IL-6, which exhibits various activities on a wide variety of cells, including lymphocytes, DCs, and keratinocytes. The IL-6 receptor is a protein complex consisting of an IL-6 receptor subunit (IL-6R) and IL-6 signal transducer glycoprotein 130 (gp130). Furthermore, STAT3 is one of the key components for IL-6 receptor signaling whereby IL-6 can stimulate keratinocyte proliferation. IL-6 induces the production of C-reactive protein, which can induce an inflammatory M1 phenotype in macrophages. IL-6 enhances AMPs through direct signaling and through IL-17 as IL-6 mediates expansion of Th17 lymphocytes. The essential involvement of IL-6 in the skin wound healing process is evidenced by delayed wound healing in IL- $6^{-/-}$mice. ${ }^{67,68}$

IL-17A and IL-22. IL-17A and IL-22 are two members of the cytokine family with substantial roles in host defense and other immunoregulatory functions. ${ }^{25,36,39,69-72}$ IL-17 is not only the master cytokine of Th17 cells but is also produced by $\mathrm{CD} 8^{+}$ $\mathrm{T}$ cells and innate lymphocytes, such as $\gamma \delta \mathrm{T}$ cells, NK cells, and NKT cells. ${ }^{73}$ IL-22 is produced by Th22 cells and minor subsets of other T cells and NK cells. Subsets of Th22 cells are resident in human skin, where they act as sentinel cells and promote keratinocyte migration. ${ }^{72}$ Skin-resident $\mathrm{T}$ cells produce increased levels of IL-17A early upon skin injury and UV-induced skin damage. ${ }^{25,30}$ The requirement for IL-17A for the normal wound healing response has been demonstrated in a mouse model, where IL-17A ${ }^{-/-}$mice showed delayed closure of incisional wounds compared with wild-type controls. ${ }^{25}$ IL-17A participates functionally in the healing response by augmenting the skin antimicrobial barrier and by regulating epidermal regeneration and differentiation. ${ }^{25,28} \mathrm{IL}-17 \mathrm{~A}$ signaling is mediated through IL-17 receptor A (IL-17RA) and IL-17RC, ${ }^{74,75}$ and keratinocytes upregulate IL-17RA upon skin injury. ${ }^{25}$ In vivo, IL-17A produced by the enigmatic murine dendritic epidermal $\gamma \delta \mathrm{T}$ cell population (DETC) induces epidermal murine $\beta$-defensin 3 (hBD2 ortho$\log$ ), S100A8, and Reg3 $\gamma$ (REG3A ortholog). The repair function of IL-17A in acute wounds is supported by several findings: recombinant IL-17A restores defective wound healing and AMP expression in IL-17A ${ }^{-1-}$ skin $^{25}$; skin-resident $\mathrm{T}$ cells, which are proficient in IL-17A production, are dysfunctional in nonhealing wounds ${ }^{76}$; and IL-17A is decreased at wound sites in severe burn wound patients who are highly susceptible to infections and sepsis. ${ }^{77}$ Furthermore, patients with genetic mutations limiting the levels of IL-17A, such as Job's syndrome, suffer from recurring mucocutaneous infections and ulcers. $^{78,79}$ Whether repair of such wounds may be improved by therapeutic targeting of skin-resident $\mathrm{T}$ cells to produce IL-17A or recombinant IL-17 is not yet known.

IL-22 mediates its functions by binding to its heterodimeric receptor consisting of IL-10 receptor $\beta 2$ (IL-10R $\beta 2$ ) and IL-22 receptor (IL-22R) and activating signaling pathways, which stimulate STAT3 phosphorylation and nuclear translocation. ${ }^{80-84}$ In vitro studies have suggested that IL-22 signals to epithelial keratinocytes of the skin to promote proliferation and migration and inducing AMPs. ${ }^{85,86}$ An essential role for IL-22 in the wound healing response has been demonstrated in IL-22 $2^{-/-}$mice. The delayed wound healing response in IL-22 $2^{-1-}$ mice has been attributed to defective fibronectin and collagen production by fibroblasts and impaired myofibroblast differentiation rather than to keratinocyte-mediated effects. ${ }^{87}$ 


\section{microRNA}

Changes in microRNA (miR) during wound healing have recently received considerable attention. These molecules suppress target mRNA expression through a complementary sequence usually in the 3'UTR and affect several genes involved in the innate immune response. Micro RNA (miR)-16, -20a, -21, -106a -130a, and -203 have been shown to be overexpressed in venous leg ulcer patients. ${ }^{88}$ They contribute to delayed wound healing through inhibiting growth factor signaling and reepithelialization. miR-203 is also increased in psoriasis and its targets include p63, suppressor of cytokine signaling 3 (SOCS3), and IL- $8,{ }^{89}$ whereas miR-21 and miR-130a target the leptin receptor. ${ }^{88}$ These miRNAs appear to serve restoration of normal keratinocyte differentiation. Studies led by Pivarsci demonstrated that miR-146 acts as a regulatory element in keratinocyte innate immunity. miR-146 suppresses the production of inflammatory mediators under homeostatic conditions, serves as a negative feedback regulator following TLR2 activation, and represses neutrophil chemotaxis. ${ }^{90}$ Its overexpression in human psoriatic skin has been suggested to reflect insufficient compensation of overt skin inflammation. ${ }^{91}$ Furthermore, miR-146 targets sma and mothers against decapentaplegic-related protein 4 (SMAD4) and thus may inhibit the TGF $\beta$ induction of the M2 phenotype. ${ }^{92}$ miR-21 appears to play a substantial role in the macrophage switch and is discussed further below.

\section{Switch from inflammation to repair}

As inflammation achieves its goals and the wound is cleared of contamination, the acute wound healing process and inflammatory stage move to a reparative stage associated with keratinocyte proliferation, the development of granulation tissue, and keratinocyte migration. It is at this point that chronic wounds stall (Fig. 2a-c). One of the major events at this time is a change in the phenotype of macrophages from an inflammatory and microbicidal phenotype, grouped as M1 macrophages, secreting IL-1, TNF $\alpha$, IL-6, IL-12, MMPs, and other cytokines, to an anti-inflammatory, regulatory, and reparative phenotype, classed and grouped as M2, producing arginase, TGF $\beta$, CCL18, PGE2, and IL-10 (Fig. 4). Because of the complexity of macrophage biology, we refer to two excellent reviews. ${ }^{93,94}$ Recent studies suggest multiple pathways by which macrophages are induced to develop into M2 and M2-like macrophages. One pathway occurs through an IL-4/IL-13-dependent signaling cascade, ${ }^{95}$ a second is mediated through TLR and IL-1R signaling and adenosine-sensing

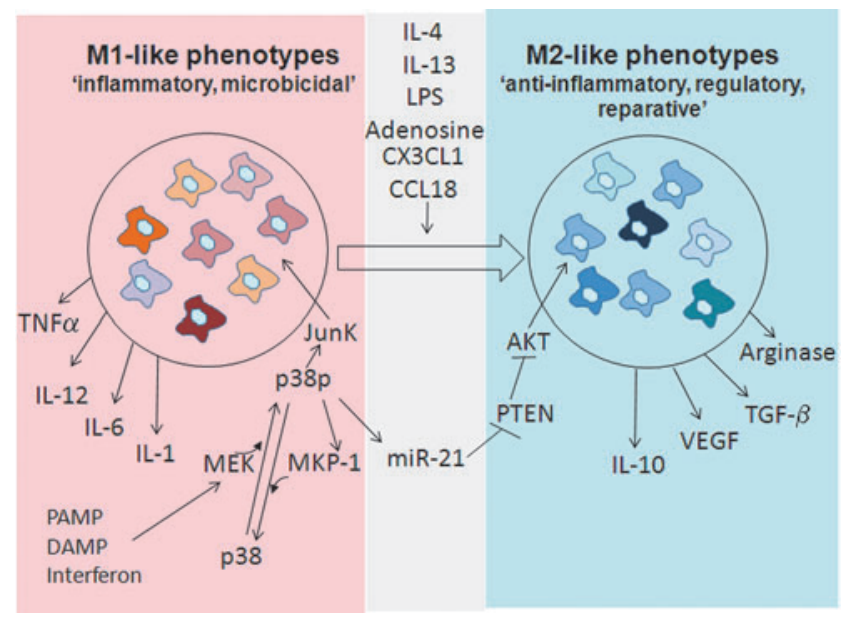

Figure 4. Macrophage plasticity in wound healing. Macrophages play multiple roles in wound healing. In the early stages of wound healing, macrophages release inflammatory cytokines that promote the inflammatory response by recruiting and activating additional leukocytes. Macrophages are also important for decontaminating the wound from microbes and clearing apoptotic cells, thereby paving the way for the resolution of inflammation and the beginning of the proliferative phase of wound healing. As the microenvironment changes within the wound bed, macrophages undergo a phenotypic switch to an anti-inflammatory, regulatory, and reparative state, which stimulates keratinocytes, fibroblasts, and endothelial cells to promote tissue regeneration. In this way, macrophages promote the transition to the proliferative phase of healing. Multiple pathways are critical in this macrophage switch from M1 to M2 and include IL-4, IL-13, TLR stimulation, adenosine signaling, CXCL1, and CCL18. Furthermore, miRNA-21 targets phosphatase with a tensin motif (PTEN) and subsequent reduction in PTEN extends the activation of protein kinase $B$ (AKT), which turns off the inflammatory state and promotes the anti-inflammatory state.

receptor $\mathrm{A}(2 \mathrm{~A}) \mathrm{R},{ }^{56,95,96}$ a third is mediated by CCL18, ${ }^{97}$ and a fourth involves CX3CL1 (fractalkine). ${ }^{57}$ While the M1 macrophages are involved in microbial decontamination and inflammation upon skin injury, M2 and M2-like macrophages induce anti-inflammatory, regulatory, and reparative functions aimed at promoting wound closure. In addition, a hybrid macrophage phenotype has been recently identified that shows some M2 as well as M1 features and is induced by CXCL4 (platelet factor 4) released by platelets at the inception of the injury response. ${ }^{98}$ The in vivo relevance of CX3CL1 and its receptor (CX3CR1) for the wound healing response is supported by the finding that its expression is highly induced during the healing of acute excisional wound ${ }^{57}$ and that CX3CR1 $1^{-1-}$ mice show delayed wound healing that could be restored by bone marrow transplants from wild-type mice, implying that the relevant site of the receptor is a bone marrow-derived cell, such as the macrophage. By comparison with wild-type, CX3CR1 $1^{-1-}$ mice showed reduced numbers of macrophages and particularly the products of anti-inflammatory macrophages such as TGF $\beta$ and VEGF at the wound site. 
This was interpreted as indicating that fractalkine is involved in the recruitment of anti-inflammatory macrophages to the wound site. ${ }^{57}$

One of the intracellular signaling pathways controlling the phenotypic switch involves p38 and miR-21. ${ }^{99,100}$ miR-21 affects several cellular actors in wound healing in multiple ways. Its promoter contains 3 activator protein 1 (AP-1) sites, a PU-1 site, and nuclear factor kappa $\mathrm{B}\left(\mathrm{NF}_{\kappa} \mathrm{B}\right)$ site. In macrophages, miR-21 plays a key role in the transition from an inflammatory to an anti-inflammatory phenotype. The p38/Jun stress pathway is activated by PAMPs and DAMPs, leading to the secretion of inflammatory cytokines, such as IL-1, TNF, and IL-6. ${ }^{101}$ In a study of a muscle repair system, Perdiguero et al. showed that the activity of p38 is controlled by mitogen-activated kinase phosphatase- 1 (MKP-1), which it induces in a feedback loop. ${ }^{99,100}$ It also induces miR-21, one of whose targets is phosphatase with a tensin motif (PTEN). The reduction in PTEN extends the activation of protein kinase B (AKT), which turns off the inflammatory state and promotes the anti-inflammatory state. It also leads, over some days, to a general reduction in cytokine secretion that is probably important for the ultimate resolution of the macrophage phase of wound healing. ${ }^{99,100}$ Under normal conditions, this process appears to possess an intrinsic time course. If the healing process fails to pace this process, the phenotype of the macrophage may become inappropriate for the stage of healing, leading to failure. Fibroblasts and keratinocytes show a response to the elevation of miR-21 that differs from macrophages and stimulates migration. ${ }^{102}$ This is of great importance for the inception of granulation tissue formation and wound closure. Thus, miR-21 appears to be involved in both the termination of the inflammatory phase of wound healing and the start of the proliferative repair phase.

miR-21 has been reported to be increased in the skin of $\mathrm{db} / \mathrm{db}$ mice, but reduced in diabetic wound healing. ${ }^{103}$ This may be the result of decreased expression in macrophages, fibroblasts, keratinocytes, or other cells. ${ }^{103}$ In $\mathrm{db} / \mathrm{db}$ mice, inhibition of p38 has been reported to improve wound healing, perhaps by reducing the inflammatory phase and delaying anti-inflammatory macrophage conversion to allow wound clearance to be completed, thus allowing healing. ${ }^{104}$ This is supported by the prolonged secretion of chemokines in the diabetic mouse. ${ }^{105}$ By contrast, in venous ulcers, miR-21 has been reported to be elevated. ${ }^{106}$ It is also consistent with the observation that the addition of macrophages induced with IL-4 or IL-10 delays wound healing in $\mathrm{db} / \mathrm{db}$ mice ${ }^{107}$ Thus, it is possible that venous ulcers and diabetic ulcers each show a derangement of the macrophage phenotypic switch, but in different ways, in each case important to an inappropriate immune response. In venous ulcers, oxidative stress may activate p38, leading to a premature induction of the anti-inflammatory macrophage phenotypes. As this process follows an intracellular program through to a decline in macrophage activity, the process may be prematurely and inappropriately shut down. In diabetic ulcers, the inflammatory process may just never reach the completion, perhaps through inadequate nutritional supply.

An alternative mechanism for the failure of the macrophage phenotype switch is that it is impaired by extracellular conditions in the wound. Separate reports using two different mouse models of nonhealing wounds ${ }^{108,109}$ have demonstrated that iron overloading and sustained inflammasome activation of macrophages results in defective transition from an inflammatory M1 to a prohealing M2 phenotype. Similar mechanisms have long been suggested for human patients. ${ }^{110}$

\section{CONCLUSION}

The innate immune system comprises a network of interacting mechanisms that provide a rapid response to clear microbial contamination upon skin injury. In the development of chronic wounds, this process stalls in the late inflammatory stage. The major defect in nonhealing wounds occurs at the phenotypic switch from inflammatory macrophages to an anti-inflammatory phenotype. This step is controlled by IL-4/IL-13, TLR activation, adenosine, and fractalkine and is influenced by IL-1 and involves a signal transduction pathway whose function depends on a calibrated activity of the stress-associated MAPK, p38. Active p38 not only controls the secretion of inflammatory cytokines but also induces miR-21 that indirectly activates $A K T$ and induces the anti-inflammatory macrophage phenotype. In fibroblasts and keratinocytes, it induces granulation tissue and migration. Interference with this mechanism leads to delayed wound healing and the system shows abnormalities in chronic wounds.

\section{ACKNOWLEDGMENTS AND FUNDING SOURCES}

Dr. A.S.M. is the recipient of an NIH Career Development Award 5K08 AR063729-02 and receives funds from the Department of Dermatology 
at Duke University, Dr. J.N.M. has no external funding sources.

\section{AUTHOR DISCLOSURE AND GHOSTWRITING}

No competing financial interests exist. The content of this article was expressly written by the authors listed. No ghostwriters were used to write this article.

\section{ABOUT THE AUTHORS}

Amanda (Büchau) MacLeod, MD, is Assistant Professor in the Department of Dermatology at Duke University in Durham, NC. Her research in the field of cutaneous immunobiology is focused on mechanistic studies to understand the interaction between innate and adaptive immunity in the skin under homeostatic and pathologic conditions. Jonathan Mansbridge, PhD, was involved in

\section{TAKE-HOME MESSAGES}

- The innate immune system comprises a group of defense and contamination clearing functions capable of rapid deployment.

- First-line defense molecules include antimicrobial peptides, CXC chemokines secreted by fibroblasts and keratinocytes, IL-1, and TNF $\alpha$.

- Recruited neutrophils and macrophages secrete cytokines that stimulate further recruitment of immune cells.

- The inflammatory phase is limited in its duration in normal wound healing and is succeeded by a prorepair phase. A central player in this switch is a phenotypic change in the macrophage.

- Failure of this switch is a candidate for the process that leads to chronic wounds. Factors involved in the control of this step through p38 include IL-4/IL-13, TLR and adenosine, and fractalkine.

the commercial development of a live fibroblast product for the treatment of chronic wounds.

\section{REFERENCES}

1. Singer AJ, Clark RA. Cutaneous wound healing. N Engl J Med 1999;341:738-746.

2. Strbo N, Yin N, Stojadinovic O. Innate and adaptive immune responses in wound epithelialization. Adv Wound Care (New Rochelle) 2014;3:492-501.

3. Gallo RL, Nakatsuji T. Microbial symbiosis with the innate immune defense system of the skin. J Invest Dermatol 2011;131:1974-1980.

4. Cogen A, Yamasaki K, Sanchez K, et al. Selective antimicrobial action is provided by phenolsoluble modulins derived from staphylococcus epidermidis, a normal resident of the skin. $J$ Invest Dermatol 2010;130:192-200.

5. Cogen A, Yamasaki K, Muto J, et al. Staphylococcus epidermidis antimicrobial delta-toxin (phenol-soluble modulin-gamma) cooperates with host antimicrobial peptides to kill group A Streptococcus. PLoS One 2010;5:e8557.

6. Lai Y, Cogen AL, Radek KA, et al. Activation of TLR2 by a small molecule produced by Staphylococcus epidermidis increases antimicrobial defense against bacterial skin infections. J Invest Dermatol 2010;130:2211-2221.

7. Nakatsuji T, Chiang HI, Jiang SB, Nagarajan H, Zengler K, Gallo RL. The microbiome extends to subepidermal compartments of normal skin. Nat Commun 2013;4:1431.

8. Huse SM, Ye Y, Zhou Y, Fodor AA. A core human microbiome as viewed through 16S rRNA sequence clusters. PLoS One 2012;7:13.

9. Reusch MK, Mansbridge JN, Nickoloff BJ, Morhenn VB. Immunophenotyping of skin cells during healing of suction blister injury. Dermatologica 1991;183:179-183.

10. Schierle CF, De la Garza M, Mustoe TA, Galiano RD. Staphylococcal biofilms impair wound healing by delaying reepithelialization in a murine cutaneous wound model. Wound Repair Regen 2009;17:354-359.

11. Sauer K, Camper AK, Ehrlich GD, Costerton JW, Davies DG. Pseudomonas aeruginosa displays multiple phenotypes during development as a biofilm. J Bacteriol 2002;184:11401154.

12. Imirzalioglu C, Sethi S, Schneider C, et al. Distinct polymicrobial populations in a chronic foot ulcer with implications for diagnostics and antiinfective therapy. BMC Res Notes 2014;7:1756.

13. Gontcharov V, Youn E, Sun Y, Wolcott RD, Dowd SE. A comparison of bacterial composition in diabetic ulcers and contralateral intact skin. Open Microbiol J 2010;4:8-19.

14. Grice EA, Segre JA. The skin microbiome. Nat Rev Microbiol 2011;9:244.

15. Polavarapu N, Ogilvie MP, Panthaki ZJ. Microbiology of burn wound infections. J Craniofac Surg 2008;19:899-253.

16. Wong VW, Martindale RG, Longaker MT, Gurtner GC. From germ theory to germ therapy: skin microbiota, chronic wounds, and probiotics. Plast Reconstr Surg 2013;132:854e-861e.

17. Dorschner RA, Pestonjamasp VK, Tamakuwala S, et al. Cutaneous injury induces the release of cathelicidin anti-microbial peptides active against group A Streptococcus. J Invest Dermatol J 2001;117:91-97.

18. James GA, Swogger E, Wolcott R, et al. Biofilms in chronic wounds. Wound Repair Regen 2008; 16:37-44.

19. Farrar D. Advanced Wound Repair Therapies. Philadelphia: Woodhead Publishing, 2010.

20. Lai Y, Di Nardo A, Nakatsuji T, et al. Commensal bacteria regulate Toll-like receptor 3-dependent inflammation after skin injury. Nat Med 2009;15: 1377-1382.

21. Edwards R, Harding KG. Bacteria and wound healing. Curr Opin Infect Dis 2004;17:91-96.

22. Menke NB, Ward KR, Witten TM, Bonchev DG, Diegelmann RF. Impaired wound healing. Clin Dermatol 2007;25:19-25.

23. Lande R, Gregorio J, Facchinetti V, et al. Plasmacytoid dendritic cells sense self-DNA coupled with antimicrobial peptide. Nature 2007;449:564-569.

24. Nielsen MM, Lovato P, MacLeod AS, et al. IL1 beta-dependent activation of dendritic epidermal T cells in contact hypersensitivity. J Immunol 2014;192:2975-2983.

25. MacLeod AS, Hemmers S, Garijo 0, et al. Dendritic epidermal $T$ cells regulate skin antimicrobial barrier function. J Clin Invest 2013;123: 4364-4374.

26. Wilmer JL, Burleson FG, Kayama F, Kanno J, Luster Ml. Cytokine induction in human epidermal keratinocytes exposed to contact irritants. J Invest Dermatol 1994;102:915-922. 
27. Braff MH, Gallo RL. Antimicrobial peptides: an essential component of the skin defensive barrier. Curr Top Microbiol Immunol 2006;306:91-110.

28. Lai Y, Li D, Li C, et al. The antimicrobial protein REG3A regulates keratinocyte proliferation and differentiation after skin injury. Immunity 2012;37:74-84.

29. Heilborn JD, Nilsson MF, Kratz G, et al. The cathelicidin anti-microbial peptide LL-37 is involved in re-epithelialization of human skin wounds and is lacking in chronic ulcer epithelium. J Invest Dermatol 2003;120:379-389.

30. MacLeod AS, Rudolph R, Corriden R, Ye I, Garijo 0, Havran WL. Skin-resident T cells sense ultraviolet radiation-induced injury and contribute to DNA repair. J Immunol 2014;192:5695-5702.

31. Brogden KA. Antimicrobial peptides: pore formers or metabolic inhibitors in bacteria? Nat Rev Microbiol 2005;3:238-250.

32. Glaser $R$, Harder J, Lange $H$, Bartels J, Christophers E, Schroder JM. Antimicrobial psoriasin (S100A7) protects human skin from Escherichia coli infection. Nat Immunol 2005;6:57-64.

33. Buchau AS. EGFR (trans)activation mediates IL-8 and distinct human antimicrobial peptide and protein production following skin injury. J Invest Dermatol 2011;130:929-932.

34. Howell MD, Boguniewicz M, Pastore $S$, et al Mechanism of HBD-3 deficiency in atopic dermatitis. Clin Immunol 2006;121:332-338.

35. Howell MD, Novak N, Bieber T, et al. Interleukin10 downregulates anti-microbial peptide expression in atopic dermatitis. J Invest Dermatol 2005; 125:738-745.

36. Buchau AS, Gallo RL. Innate immunity and antimicrobial defense systems in psoriasis. Clin Dermatol 2007;25:616-624.

37. Ong PY, Ohtake T, Brandt C, et al. Endogenous antimicrobial peptides and skin infections in atopic dermatitis. N Engl J Med 2002;347:1151-1160.

38. Sorensen OE, Thapa DR, Roupe KM, et al. Injuryinduced innate immune response in human skin mediated by transactivation of the epidermal growth factor receptor. J Clin Invest 2006;116: 1878-1885.

39. Liang SC, Tan XY, Luxenberg DP, et al. Interleukin (IL)-22 and IL-17 are coexpressed by Th17 cells and cooperatively enhance expression of antimicrobial peptides. J Exp Med 2006;203:2271-2279.

40. Agerberth B, Charo J, Werr J, et al. The human antimicrobial and chemotactic peptides LL-37 and alpha-defensins are expressed by specific lymphocyte and monocyte populations. Blood 2000;96:3086-3093.

41. Buchau AS, Morizane S, Trowbridge J, et al. The host defense peptide cathelicidin is required for NK cell-mediated suppression of tumor growth. J Immunol 2010;184:369-378.

42. Liu PT, Stenger S, Li H, et al. Toll-like receptor triggering of a vitamin D-mediated human antimicrobial response. Science 2006;311:1770-1773.
43. Schauber J, Dorschner RA, Coda AB, et al. Injury enhances TLR2 function and antimicrobial peptide expression through a vitamin D-dependent mechanism. J Clin 2007;117:803-811.

44. Dressel S, Harder J, Cordes J, et al. Differential expression of antimicrobial peptides in margins of chronic wounds. Exp Dermatol 2010;19:628-632.

45. Buchau AS, Hassan M, Kukova G, et al S100A15, an antimicrobial protein of the skin: regulation by $E$. coli through Toll-like receptor 4 . J Invest Dermatol 2007;127:2596-2604.

46. Mosser DM, Edwards JP. Exploring the full spectrum of macrophage activation. Nat Rev Immunol 2008:8:958-969.

47. Devalaraja RM, Nanney LB, Du J, et al. Delayed wound healing in CXCR2 knockout mice. J Invest Dermatol 2000;115:234-244.

48. Milatovic S, Nanney LB, Yu Y, White JR, Richmond $A$. Impaired healing of nitrogen mustard wounds in CXCR2 null mice. Wound Repair Regen 2003;11:213-219.

49. Opdenakker G, Van den Steen PE, Dubois B, et al. Gelatinase $B$ functions as regulator and effector in leukocyte biology. J Leukoc Biol 2001;69:851-859.

50. Dovi JV, He LK, DiPietro LA. Accelerated wound closure in neutrophil-depleted mice. J Leukoc Biol 2003;73:448-455.

51. Kaesler S, Bugnon P, Gao JL, Murphy PM, Goppelt A, Werner $S$. The chemokine receptor CCR1 is strongly up-regulated after skin injury but dispensable for wound healing. Wound Repair Regen 2004;12:193-204.

52. Lee P, Lee DJ, Chan C, Chen SW, Ch'en I, Jamora $\mathrm{C}$. Dynamic expression of epidermal caspase 8 simulates a wound healing response. Nature 2009;458:519-523.

53. Barone EJ, Yager DR, Pozez AL, et al. Interleukin1alpha and collagenase activity are elevated in chronic wounds. Plast Reconstr Surg 1998;102: 1023-1027.

54. Mizumoto N, Kumamoto T, Robson SC, et al. CD39 is the dominant Langerhans cell-associated ecto-NTPDase: modulatory roles in inflammation and immune responsiveness. Nat Med 2002;8:358-365

55. Thomay AA, Daley JM, Sabo E, et al. Disruption of interleukin-1 signaling improves the quality of wound healing. Am J Pathol 2009;174:2129-2136.

56. Ishida Y, Kondo T, Kimura A, Matsushima K, Mukaida N. Absence of IL-1 receptor antagonist impaired wound healing along with aberrant NFkappaB activation and a reciprocal suppression of TGF-beta signal pathway. J Immunol 2006;176: 5598-5606.

57. Ishida Y, Gao JL, Murphy PM. Chemokine receptor CX3CR1 mediates skin wound healing by promoting macrophage and fibroblast accumulation and function. J Immunol 2008;180:569-573.

58. Gill SE, Parks WC. Metalloproteinases and their inhibitors: regulators of wound healing. Int $J$ Biochem Cell Biol 2008;40:1334-1347.
59. Rapala K, Laato M, Niinikoski J, et al. Tumor necrosis factor alpha inhibits wound healing in the rat. Eur Surg Res 1991;23:261-268.

60. Steenfos HH. Growth factors and wound healing Scand J Plast Reconstr Surg Hand Surg 1994:28:95-105.

61. Weinstein DA, Kirsner RS. Refractory ulcers: the role of tumor necrosis factor-alpha. J Am Acad Dermatol 2010;63:146-154.

62. Leask A, Abraham DJ. TGF-beta signaling and the fibrotic response. FASEB J 2004;18:816-827.

63. Cowin AJ, Hatzirodos N, Rigden J, Fitridge R, Belford DA. Etanercept decreases tumor necrosis factor-alpha activity in chronic wound fluid. Wound Repair Regen 2006;14:421-426.

64. Mooney DP, O'Reilly M, Gamelli RL. Tumor necrosis factor and wound healing. Ann Surg 1990;211:124-129

65. Salomon GD, Kasid A, Cromack DT, et al. The local effects of cachectin/tumor necrosis factor on wound healing. Ann Surg 1991;214:175-180.

66. Mori R, Kondo T, Ohshima T, Ishida Y, Mukaida $\mathrm{N}$. Accelerated wound healing in tumor necrosis factor receptor p55-deficient mice with reduced leukocyte infiltration. FASEB J 2002; 16:963-974.

67. Lin ZQ, Kondo T, Ishida Y, Takayasu T, Mukaida $\mathrm{N}$. Essential involvement of IL-6 in the skin wound-healing process as evidenced by delayed wound healing in IL-6-deficient mice. J Leukoc Biol 2003;73:713-721.

68. McFarland-Mancini MM, Funk HM, Paluch AM, et al. Differences in wound healing in mice with deficiency of IL-6 versus IL-6 receptor. J Immunol 2010;184:7219-7228.

69. Kolls JK, McCray PB, Jr., Chan YR. Cytokinemediated regulation of antimicrobial proteins. Nat Rev Immunol 2008;8:829-835.

70. Sonnenberg GF, Fouser LA, Artis D. Border patrol: regulation of immunity, inflammation and tissue homeostasis at barrier surfaces by IL-22 Nat Immunol 2011;12:383-390.

71. Wolk K, Kunz S, Witte E, Friedrich M, Asadullah K, Sabat R. IL-22 increases the innate immunity of tissues. Immunity 2004;21:241-254.

72. Eyerich S, Eyerich K, Pennino D, et al. Th22 cells represent a distinct human $T$ cell subset involved in epidermal immunity and remodeling. J Clin Invest 2009;119:3573-3555.

73. Weaver CT, Harrington LE, Mangan PR, Gavrieli M, Murphy KM. Th17: an effector CD4 T cell lineage with regulatory $T$ cell ties. Immunity 2006:24:677-688.

74. Ely LK, Fischer S, Garcia KC. Structural basis of receptor sharing by interleukin 17 cytokines. Nat Immunol 2009;10:1245-1251.

75. Toy D, Kugler D, Wolfson $M$, et al. Cutting edge: interleukin 17 signals through a heteromeric receptor complex. J Immunol 2006; 177:36-39. 
76. Toulon A, Breton L, Taylor KR, et al. A role for human skin-resident T cells in wound healing. J Exp Med 2009;206:743-750.

77. Inatsu A, Kogiso M, Jeschke MG, et al. Lack of Th17 cell generation in patients with severe burn injuries. J Immunol 2011;187:2155-2161.

78. Ma CS, Chew GY, Simpson N, et al. Deficiency of Th17 cells in hyper lgE syndrome due to mutations in STAT3. J Exp Med 2008;205:1551-1537.

79. Milner JD, Brenchley JM, Laurence A, et al. Impaired $T(H) 17$ cell differentiation in subjects with autosomal dominant hyper-lgE syndrome. Nature 2008;452:773-776.

80. Dumoutier L, Leemans C, Lejeune D, Kotenko SV, Renauld JC. Cutting edge: STAT activation by IL19, IL-20 and mda-7 through IL-20 receptor complexes of two types. J Immunol 2001; 167:3545-3549.

81. Dumoutier L, Lejeune D, Hor S, Fickenscher H, Renauld JC. Cloning of a new type II cytokine receptor activating signal transducer and activator of transcription (STAT)1, STAT2 and STAT3. Biochem J 2003;370:391-396.

82. Kotenko SV, Izotova LS, Mirochnitchenko OV, et al. Identification, cloning, and characterization of a novel soluble receptor that binds IL-22 and neutralizes its activity. J Immunol 2001;166:7096-7103.

83. Lejeune D, Dumoutier L, Constantinescu S, Kruijer W, Schuringa JJ, Renauld JC. Interleukin-22 (IL-22) activates the JAK/STAT, ERK, JNK, and p38 MAP kinase pathways in a rat hepatoma cell line. Pathways that are shared with and distinct from IL-10. J Biol Chem 2002;277:33676-33682.

84. Xie MH, Aggarwal S, Ho WH, et al. Interleukin (IL)22, a novel human cytokine that signals through the interferon receptor-related proteins CRF2-4 and IL-22R. J Biol Chem 2000;275:31335-31339.

85. Boniface K, Bernard FX, Garcia M, Gurney AL, Lecron JC, Morel F. IL-22 inhibits epidermal differentiation and induces proinflammatory gene expression and migration of human keratinocytes. J Immunol 2005;174:3695-3702.

86. Wolk K, Sabat R. Interleukin-22: a novel T- and NK-cell derived cytokine that regulates the biology of tissue cells. Cytokine Growth Factor Rev 2006;17:367-380.

87. McGee HM, Schmidt BA, Booth CJ, et al. IL-22 promotes fibroblast-mediated wound repair in the skin. J Invest Dermatol 2013;133:1321-1329.

88. Pastar I, Khan AA, Stojadinovic 0, et al. Induction of specific microRNAs inhibits cutaneous wound healing. J Biol Chem 2012;287:29324-29335.

89. Sonkoly E, Stahle M, Pivarcsi A. MicroRNAs: novel regulators in skin inflammation. Clin Exp Dermatol 2008;33:312-315.

90. Meisgen F, Xu Landen N, Wang A, et al. MiR146a negatively regulates TLR2-induced inflammatory responses in keratinocytes. J Invest Dermatol 2014;134:1931-1940.

91. Sonkoly E, Wei T, Janson PC, et al. MicroRNAs: novel regulators involved in the pathogenesis of psoriasis? PLoS One 2007;2:e610.
92. Bostjancic E, Glavac D. Importance of microRNAs in skin morphogenesis and diseases. Acta Dermatovenerol Alp Pannonica Adriati 2008;17:95102.

93. Murray PJ, Wynn TA. Protective and pathogenic functions of macrophage subsets. Nat Rev Immunol 2011;11:723-737.

94. Mantovani A, Biswas SK, Galdiero MR, Sica A, Locati M. Macrophage plasticity and polarization in tissue repair and remodelling. J Pathol 2013;229:176-185.

95. Ferrante CJ, Pinhal-Enfield G, Elson G, et al. The adenosine-dependent angiogenic switch of macrophages to an M2-like phenotype is independent of interleukin-4 receptor alpha (IL-4Ralpha) signaling. Inflammation 2013;36:921-931.

96. Pinhal-Enfield G, Ramanathan M, Hasko G, et al. An angiogenic switch in macrophages involving synergy between Toll-like receptors 2, 4, 7, and 9 and adenosine $A(2 A)$ receptors. Am J Pathol 2003;163:711-721.

97. Schraufstatter IU, Zhao M, Khaldoyanidi SK, Discipio RG. The chemokine CCL18 causes maturation of cultured monocytes to macrophages in the M2 spectrum. Immunology 2012;135:287-298.

98. Gleissner CA, Shaked I, Erbel C, Bockler D, Katus HA, Ley K. CXCL4 downregulates the atheroprotective hemoglobin receptor CD163 in human macrophages. Circ Res 2010;106:203-211.

99. Perdiguero E, Kharraz Y, Serrano AL, MunozCanoves P. MKP-1 coordinates ordered macrophage-phenotype transitions essential for stem cell-dependent tissue repair. Cell Cycle 2012; 11:877-886.

100. Perdiguero E, Sousa-Victor P, Ruiz-Bonilla V, et al. p38/MKP-1-regulated AKT coordinates macrophage transitions and resolution of inflammation during tissue repair. J Cell Biol 2011; 195:307-322.

101. Coulthard LR, White DE, Jones DL, McDermott MF, Burchill SA. p38(MAPK): stress responses from molecular mechanisms to therapeutics. Trends Mol Med 2009;15:369-379.

102. Yang $X$, Wang J, Guo SL, et al. miR-21 promotes keratinocyte migration and re-epithelialization during wound healing. Int J Biol Sci 2011;7:685-690.

103. Madhyastha R, Madhyastha $H$, Nakajima $Y$, Omura S, Maruyama M. MicroRNA signature in diabetic wound healing: promotive role of miR21 in fibroblast migration. Int Wound $\mathrm{J} 2012$; 9:355-361.

104. Medicherla S, Wadsworth S, Cullen B, et al. p38 MAPK inhibition reduces diabetes-induced impairment of wound healing. Diabetes Metab Syndr Obes 2009;2:91-200.

105. Wetzler C, Kampfer H, Stallmeyer B, Pfeilschifter $J$, Frank S. Large and sustained induction of chemokines during impaired wound healing in the. J Invest Dermatol 2000;115:245-253.

106. Pastar I, Khan AA, Stojadinovic 0, et al. Induction of specific microRNAs inhibits cutaneous wound healing. J Biol Chem 2012;287:2932429335.

107. Jetten N, Roumans N, Gijbels MJ, et al. Wound administration of M2-polarized macrophages does not improve murine cutaneous healing responses. PLoS One 2014;9:e102994.

108. Mirza RE, Fang MM, Weinheimer-Haus EM, Ennis WJ, Koh TJ. Sustained inflammasome activity in macrophages impairs wound healing in type 2 diabetic humans and mice. Diabetes 2014;63:1103-1114.

109. Sindrilaru A, Peters T, Wieschalka S, et al. An unrestrained proinflammatory M1 macrophage population induced by iron impairs wound healing in humans and mice. J Clin Invest 2011;121:985-987.

110. Sindrilaru A, Scharffetter-Kochanek K. Disclosure of the culprits: macrophages-versatile regulators of wound healing. Adv Wound Care (New Rochelle) 2013;2:357-368.

\section{Abbreviations and Acronyms}

$\mathrm{A}(2 \mathrm{~A}) \mathrm{R}=$ adenosine type $2 \mathrm{~A}$ receptor

$A K T=$ protein kinase $B$

$\mathrm{AMP}=$ antimicrobial peptide and protein

AP-1 = activator protein 1

ASC $=$ apoptosis-associated speck-like protein containing CARD

ATP $=$ adenosine triphosphate

$\mathrm{CAMP}=$ cathelicidin antimicrobial peptide

$\mathrm{CCL}=$ group of chemokine ligands characterized by two adjacent cyteins

CRAMP $=$ cathelicidin-related antimicrobial peptide

$\mathrm{CXCL}=$ class of chemokines characterized by the sequence cysteine, any amino acid, cysteine.

$C X C R=C X C$ chemokine receptor

$\mathrm{DAMP}=$ danger-associated molecular pattern

$\mathrm{db} / \mathrm{db}=$ mice lacking the leptin receptor

$\mathrm{DC}=$ dendritic cell

$\mathrm{DETC}=$ dendritic epidermal $\gamma \delta$ T cells

dsRNA $=$ double-stranded ribonucleic acid

eATP $=$ extracellular adenosine triphosphate

$\mathrm{ECM}=$ extracellular matrix

$\mathrm{EF}=$ calcium-binding motif

$E L R=$ asparagine leucine arginine

$\mathrm{hBD}=$ human $\beta$-defensin

$\mathrm{IFN}=$ interferon

IGF $=$ insulin-like growth factor

$\mathrm{IL}=$ interleukin

$\mathrm{KC}=$ keratinocyte

$\mathrm{KGF}=$ keratinocyte growth factor

LPS = lipopolysaccharide

MAPK $=$ mitogen activated protein kinase

MIP-2 = macrophage inflammatory protein 2-alpha

$\mathrm{miR}=$ micro RNA

MKP-1 $=$ mitogen-activated kinase phosphatase-1

$\mathrm{MMP}=$ matrix metalloproteinase

NALP3 $=$ NACHT, LRR and PYD domains-containing protein 3 


$\begin{gathered}\text { Abbreviations and Acronyms } \\ \text { (Cont.) }\end{gathered}$
$N F \kappa B=$ nuclear factor kappa B
$N K=$ natural killer cell
$\mathrm{NKT}=$ natural killer T cell
$\mathrm{NO}=$ nitric oxide
$\mathrm{p} 38=$ stress-related mitogen-activated
$\quad$ kinase
$\mathrm{PAMP}=$ pathogen-associated molecular pattern
$\mathrm{PBMC}=$ peripheral blood mononuclear cells
$\mathrm{PGE2}=$ prostaglandin $\mathrm{E} 2$

$\mathrm{PRR}=$ pathogen recognition receptor

PTEN $=$ phosphatase with a tensin motif

PU-1 = master transcription factor of the myeloid system

$\mathrm{RAGE}=$ receptor for advanced glycation endproducts

REG3A = regenerating islet-derived protein $3 \mathrm{~A}$

RNase7 = ribonuclease 7

$\mathrm{ROS}=$ reactive oxygen species

SMAD4 $=$ sma and mothers against decapentaplegic-related protein 4
STAT3 $=$ signal transducer and activator of transcription 3

SOCS3 $=$ suppressor of cytokine signaling 3

TGF $\beta=$ tumor growth factor $\beta$

$\mathrm{Th}=\mathrm{T}$ helper cell

$\mathrm{TLR}=$ Toll-like receptor

TNF $=$ tumor necrosis factor

TNF-Rp55, TNF-Rp75=

TNF receptors

$\mathrm{UV}=$ ultraviolet

VEGF $=$ vascular endothelial growth factor 